\title{
Prognosis following the use of complementary and alternative medicine in women diagnosed with breast cancer
}

\author{
Juliann Saquib, MPH, PhD, Barbara A. Parker, MD, Loki Natarajan, PhD, Lisa Madlensky, \\ PhD, Nazmus Saquib, PhD, Ruth E. Patterson, PhD, Vicky A. Newman, MS, RD, and John P. \\ Pierce, PhD \\ Cancer Prevention and Control Program, Rebecca and John Moores UCSD Cancer Center, \\ University of California, San Diego, La Jolla, CA 92093-0645
}

\begin{abstract}
Objective-The purpose of this study was to assess whether CAM use affected breast cancer prognosis in those who did not receive systemic therapy.
\end{abstract}

Design-Secondary data analysis of baseline/survey data from the Women's Healthy Eating and Living Study (WHEL). 2562 breast cancer survivors participating in the study completed baseline assessments and a CAM use questionnaire. Cox regression models were conducted to evaluate the use of CAM modalities and dietary supplements on time to an additional breast cancer event (mean follow-up $=7.3$ years).

Setting-A US-based multi-site randomized dietary trial.

Outcome-Time to additional breast cancer events.

Results-The women who did not receive any systemic treatment had a higher risk for time to additional breast cancer events (HR=1.9, 95\% CI: 1.32, 2.73) and for all-cause mortality (HR=1.7, $95 \%$ CI: 1.06, 2.73) compared to those who had received systemic treatment. Among 177 women who did not receive systemic treatment, CAM use was not significantly related to additional breast cancer events. There were no significant differences between high supplement users ( $\geq 3$ formulations per day) and low supplement users in either risk for additional breast cancer events.

Conclusion-The risk for an additional breast cancer event and/or death was higher for those who did not receive any systemic treatments; the use dietary supplements or CAM therapies did not change this risk. This indicates that complementary and alternative therapies did not alter the outcome of breast cancer and should not be used in place of standard treatment.

\section{Keywords}

breast cancer; complementary and alternative medicine; dietary supplements; long- term prognosis; alternative cancer treatment

(C) 2012 Elsevier Ltd. All rights reserved.

CORRESPONDING AUTHOR: John P. Pierce, Ph.D., Cancer Prevention and Control Program. Rebecca and John Moores UCSD Cancer Center. University of California, San Diego 3855 Health Sciences Drive, 0901, La Jolla, CA 92093. Phone: (858) 822-2380, Fax (858) 822-2399, jppierce@ucsd.edu.

Publisher's Disclaimer: This is a PDF file of an unedited manuscript that has been accepted for publication. As a service to our customers we are providing this early version of the manuscript. The manuscript will undergo copyediting, typesetting, and review of the resulting proof before it is published in its final citable form. Please note that during the production process errorsmaybe discovered which could affect the content, and all legal disclaimers that apply to the journal pertain.

CONFLICT OF INTEREST

All of the authors declare that there are no conflicts of interest for this paper. 


\section{INTRODUCTION}

Improvements in breast cancer recurrence and survival have consistently been associated with the use of systemic cancer treatments (chemotherapy and anti-estrogen therapy) following surgery. ${ }^{1-3}$ Despite the effectiveness of these treatments, a significant proportion of women do not receive them. ${ }^{4-5} \mathrm{~A}$ decision by the patient to decline treatment has been one of the primary reasons for the underuse of systemic treatment. ${ }^{5-6}$ It is plausible that not all patients understand the impact of their decisions regarding treatment. ${ }^{5}$ Issues such as patient misunderstanding, or lack of information regarding the effectiveness of treatments, and fear of side effects have been associated with not pursuing these treatments. ${ }^{7-8}$ Another potential factor is the untested belief that using alternative therapies and/or having a healthy lifestyle may be protective against cancer recurrence or death. ${ }^{9-11}$

Approximately $80 \%$ of breast cancer patients and survivors use some form of complementary and alternative medicine (CAM), ${ }^{12}$ which has been defined as a group of diverse medical and health care systems, practices, and products that are not presently considered to be part of conventional medicine. ${ }^{13}$ Dietary supplements such as vitamins, minerals and herbals remain the most commonly used form of CAM. ${ }^{14-15}$ Even though several studies have examined the prevalence and patterns of CAM use following a breast cancer diagnosis, ${ }^{16-20}$ few studies have reported the impact on breast cancer outcomes. ${ }^{21-22}$ To date, the literature has suggested that there is insufficient evidence to determine the effect of CAM therapies on breast cancer prognosis. ${ }^{23}$ One small observational study $(n=33)$ that examined the use of biologically-based CAM therapies as a primary treatment for breast cancer found that patients who used only CAM therapies had higher rates of recurrence and death than those who used standard treatment. ${ }^{24}$

Because the use of CAM therapies has been largely studied among breast cancer patients who have used conventional treatments, the impact of CAM use among women who have not received standard treatments is unknown. The Women's Healthy Eating and Living (WHEL) Study provided a unique opportunity to investigate the potential risks or benefits of alternative therapies due to the extensive data collected on CAM use, including dietary supplements, as well as a large sample size and long follow-up. Since the WHEL dietary intervention did not affect prognosis, ${ }^{25}$ the trial participants were treated as a cohort of breast cancer survivors. The purpose of this study was to determine whether CAM use, including dietary supplements, was associated with risk for additional breast cancer events and death among those women who did not receive any systemic cancer therapies.

\section{METHODS}

\section{Study Design and Participants}

This project was part of a large multisite clinical trial investigating the efficacy of a dietary intervention to reduce risk for breast cancer recurrence. The WHEL Study enrolled participants at seven clinical sites between 1995 and 2000; the institutional review boards at each site approved the protocol and all participants provided written, informed consent. Details of the study protocol are described elsewhere. ${ }^{26}$ Major eligibility criteria included diagnosis within the past 4 years of primary operable invasive stage I $(\geq 1 \mathrm{~cm})$, II, or IIIA breast carcinoma (American Joint Committee on Cancer, AJCC $4^{\text {th }}$ edition); age 18-70 years at the time of diagnosis; no current or planned chemotherapy; no evidence of recurrent disease or new breast cancer since completion of initial treatment; and no other cancer in the past 10 years. As previously reported, the intervention aimed to promote the adoption of a high vegetable, fruit, fiber, and low fat diet; however, the intervention did not address the use of complementary and alternative medicines such as dietary supplements (neither encouraged nor restricted). ${ }^{25}$ The present analyses included WHEL participants who 
completed baseline assessments for medical information (specifically treatment) and dietary supplement use. Certain analyses were conducted on the sub-group of women who completed a follow-up CAM use questionnaire $(\mathrm{n}=2562)$.

\section{Measures}

Demographic and medical information-Participants self-reported demographic and medical information at study enrollment. Medical information, including the types of cancer treatments (type of surgery, radiation, chemotherapy, and anti-estrogen therapy) each patient received was confirmed by reviewing the patient's medical record. Co-morbid conditions were classified in the following categories:

- Diabetic conditions: prediabetic/diabetes requiring insulin, and diabetes not requiring insulin.

- Cardiovascular conditions: any high cholesterol requiring pills, high blood pressure, angina, peripheral arterial disease, or other heart related problems.

- Digestive conditions: any stomach or duodenal ulcer, diverticulitis, ulcerative colitis, Crohn's disease, pancreatitis, intestinal or polyp removal, irritable bowel syndrome, or malabsorption syndrome.

- Arthritis

Complementary and alternative medicine-The CAM assessment was administered over telephone between January 2003 and May 2004. The assessment included 17 listed CAM therapies according to the National Center for Complementary and Alternative Medicine. ${ }^{13}$ The therapies included the following:

- Whole medical systems: acupuncture, homeopathic medicine, naturopathic medicine

- Mind-body medicine: biofeedback, visual imagery, meditation/relaxation, yoga, chanting/music therapy, spiritual healing, qigong/tai chi

- Body-based medicine: chiropractic medicine \& massage therapy

- Energy medicine: crystals, magnets, reiki, therapeutic touch

- Biologically-based medicine: dietary supplements

Interviewers asked whether each CAM practice had ever been used. The participant was also given the opportunity to list any additional CAM practices that had not been included on the list. For this analysis, the participants were categorized as either having used at least one CAM therapy for cancer purposes (CAM user) or having never used any CAM therapies (CAM non-user). Dietary supplement use was tested independently and was not used in defining CAM use.

Dietary Supplements-In the WHEL Study, detailed data on dietary supplement use were collected at the baseline assessment. During each of the four recalls, participants were asked to name all dietary supplement formulations and the number of tablets or capsules of each formulation they had ingested during the previous 24 hours. Supplements were categorized according to formulation type (i.e., multivitamin, minerals, or herbal remedies). Participants' total number of formulations was taken into account, and any participant who used more than three formulations per day was categorized as 'high supplement users.' Detailed protocols regarding data collection and the dietary supplement database have been described elsewhere. ${ }^{27-28}$ 
Health Behaviors: Smoking Status and Physical Activity-At baseline, participants completed a questionnaire on their personal habits that included standard questions on smoking history and a 9-item physical activity assessment. ${ }^{29}$ The frequency, duration and intensity of physical activity were converted into metabolic equivalents (METs). Total energy expenditure was obtained by weighting time spent per week by METs: mild, moderate, and vigorous activity were weighted as 3, 5, and 8 METS, respectively. ${ }^{30}$ Walking was weighted 2 to 6 METs according to intensity. As per Holmes, ${ }^{31}$ we chose $540 \mathrm{MET}-\mathrm{min} / \mathrm{wk}$ as the recommended level of physical activity for breast cancer survivors. ${ }^{25}$

Outcomes-Primary outcomes were time to additional breast cancer events and all-cause mortality (time to death). Time to additional breast cancer events was the time from study enrollment (1995-2000) to the development of an additional breast cancer event, which was defined as a recurrence from the original cancer or developing a new breast cancer. Followup time for breast cancer events was censored at the earliest of the following: 1) time of a participant's non-breast cancer death, 2) the last documented staff contact date, or 3) study completion (June 2006). For all-cause mortality, follow-up time was censored at the time of the last documented staff contact date or at study completion.

\section{Analytic Methods}

Descriptive statistics were computed on all variables including demographic information, health behaviors, and CAM use, as well as tumor and treatment characteristics. We examined correlates associated with systemic treatment use such as chemotherapy and antiestrogen therapy in order to determine differences in participant characteristics between those who had received systemic treatment to those who had not received systemic treatment. Cox proportional hazard regression was used to determine the unadjusted association between the use of systemic treatment and each outcome (time to additional breast cancer event and all-cause mortality). The reference group consisted of those women who received either chemotherapy, anti-estrogen therapy or both; the comparison group included those who had not received any systemic treatments. The hazard ratios and associated $95 \%$ confidence intervals were the measures of association. Additionally, models were adjusted for age, tumor stage and time since diagnosis, each of which were related to additional breast cancer events and all-cause mortality.

Further, Cox proportional hazard regressions were used to determine the impact of CAM use in the absence of systemic treatment. Among the 'no systemic treatment' group ( $\mathrm{n}=177)$,we tested the association between the use of CAM (non-users vs. users) and time to an additional breast cancer event as well as supplement use (low vs. high) and time to an additional breast cancer event. All-cause mortality was not tested in this sub-group because of the small number of events. The reference group for the first model included women who had not used any CAM therapies for cancer purposes, and the reference group for the second model included women who had used less than three dietary supplement formulations. The hazard ratios and corresponding 95\% confidence intervals were the measures of association.

\section{RESULTS}

The WHEL Study included 177 participants who did not receive systemic therapy following a breast cancer diagnosis. As shown in Table 1, if participants did not get systemic therapy, then the risk of an additional breast cancer event increased by $90 \%$ (HR=1.9, 95\% CI: 1.32, 2.73 ), and the risk of death increased by $70 \%$ (HR=1.7, 95\% CI: 1.06, 2.73). Participant characteristics differed slightly depending on the receipt of systemic therapy. Women who did not receive systemic treatment were less educated and were diagnosed early in the study 
$(\mathrm{p}<.05)$. In addition, those without systemic treatment appeared more likely to have a comorbid condition, although this was only borderline statistically significant (Table 2).

Eighty percent of the women reported using at least one of the CAM modalities on a previous occasion for any purpose. Approximately half of them reported using a CAM modality for cancer purposes, which included alleviating treatment side effects. There were only slight differences in CAM modality use by systemic therapy use (Table 3). A larger percentage of women who had not received systemic treatment reported the use of naturopathic medicine than women who had received systemic treatment $(9.9 \%$ vs 5.7\%, p $<$.04). Mind-body medicine (e.g., meditation, yoga, spiritual healing) was the most commonly reported domain (40\%) of CAM for cancer. Use of the other three domains for cancer purposes (whole medicine system, body-based therapies and energy-based therapy) were used by less than $5 \%$ of the sample.

Among all participants, $85 \%$ of the women used at least one supplement formulation per day (Table 4). Those who did not receive systemic therapy were more likely to use herbal remedies $(\mathrm{p}<.005)$, as well as some vitamin supplements, particularly B-complex $(\mathrm{p}<$. 003). The average number of formulations used per day was three; groups were equally likely to have reported the use of more than three supplements per day (Figure 1).

CAM users without systemic treatment had a similar risk for additional breast cancer events as non-CAM users without systemic treatment (Table 5). In the second model, there were no significant differences between high supplement users and low supplement users for additional breast events. Both models were adjusted for age, tumor stage and time since diagnosis. Further, there were no significant relationships between CAM use $(\mathrm{HR}=1.26$, $95 \%$ CI: $0.98,1.62)$ or supplement use $(\mathrm{HR}=1.03,95 \%$ CI: $0.86,1.23)$ with additional breast cancer events in the group who had received systemic treatment. Additionally, models that tested statistical interactions were not significant, which indicated that neither CAM use $(\mathrm{p}=0.26, \mathrm{p}=0.87)$ nor supplement use $(\mathrm{p}=0.81, \mathrm{p}=0.73)$ modified the relationship between systemic treatment use and additional breast cancer events.

\section{DISCUSSION}

Our results demonstrated that breast cancer events and death were more likely for those who did not receive any systemic treatment and using dietary supplements or additional CAM therapies did not change the risk for either outcome. Our first finding was in congruence with earlier studies that have shown that those who did not receive adequate systemic treatment were at a higher risk of recurrence. ${ }^{3,32-33}$ Studies have suggested that prognosis was better for women who had a combination of chemotherapy and/or anti-estrogen treatment. ${ }^{34}$ There are various reasons why breast cancer patients do not receive the systemic cancer treatments in oncology: patient refusals account for approximately one-third of the cases, in addition to absence of a physician recommendation and health care barriers. ${ }^{4,6}$ It is possible that beliefs in complementary and alternative medicine may contribute to a patient's decision to decline systemic treatment.

In women who had not used any systemic treatments, the risk of additional breast cancer events did not differ by CAM use. Our results support earlier studies' conclusion that the exclusive use of alternative therapies do not improve breast cancer outcomes; however, CAM may be useful as supportive care for cancer patients. ${ }^{23,}{ }^{35}$ Although this was not within the scope of the present study, the majority of scientific evidence in favor of CAM therapies has been for addressing components of quality of life such as pain, fatigue, and depression. Studies have suggested potential benefits for the following therapies: acupuncture and massage, ${ }^{36-37}$ meditation, guided imagery and relaxation..$^{38-40}$ In addition 
to alleviating symptoms, these therapies are considered to be gentle, noninvasive techniques that can be easily integrated into comprehensive cancer care. ${ }^{36}$

The existing concern regarding CAM use among breast cancer patients is the high prevalence of supplement use despite the lack of evidence for its efficacy. We investigated heavy supplement use among those who had not received systemic treatment and found that heavy supplement users did not have a significantly different risk for additional breast cancer events compared to low supplement users. In terms of breast cancer prognosis, nutrient-based supplements (vitamins and minerals) have not shown benefit or harm among those who have received the appropriate cancer treatments. ${ }^{41-42}$ Others found increased rates of recurrence and death among patients who used various high-dose vitamins and herbal therapies in place of treatments such as surgery and systemic therapies. ${ }^{24}$ While few studies have examined the relationship between herbal remedies and breast cancer outcomes, findings have indicated potential harm associated with certain herbal supplements, such as those with blood thinning properties or estrogenic effects. ${ }^{36,43}$ Until there are sufficient data to determine the efficacy of herbal supplements, oncologists have advised patients to use caution regarding these products.

We acknowledge our study has limitations and the findings may not be generalizable to all women who have had a breast cancer diagnosis. The study sample may not fully represent the group of women who do not receive systemic treatments. Earlier studies have reported that lack of adherence to cancer treatment is often associated with ethnic minorities and lower socioeconomic status ${ }^{4}$ however, our study was predominantly non-Hispanic white. Our study does not discriminate among the types of systemic treatments offered to patients nor the changes in treatment regimens that have occurred since 2000. Secondly, CAM use was broadly defined and its measurement was cross-sectional; we did not have data regarding the duration of use per therapy nor the statistical power to test each therapy. Further, within the sample for this study, 452 (treatment $n=428$, no treatment $n=24$ ) women did not complete the CAM survey possibly because it was administered during the follow-up period. There was a higher rate of events among those who did not complete the survey; however, the rate of events was equivalent between those who received systemic treatment and those who did not.

The study sample was both a strength and weakness. It is unique to have data on women who underuse conventional medicine because they do not often enroll in research studies, but it is difficult to make conclusions based on a small group of women. Our results should be interpreted with caution given that we may not have adequate statistical power. Other strengths of the study include the long follow-up period and sufficient data for several covariates that are known to be associated with breast cancer prognosis and were controlled for in the multivariate models (i.e., tumor and treatment characteristic). Since this was one of the first observational studies to examine CAM use as an alternative to conventional treatment, further studies need to continue to investigate the effects of these therapies.

This study adds to the body of literature needed to address the public health concerns surrounding CAM use among cancer patients. Although complementary and alternative therapies have not always been respected by conventional medical practitioners, their emergence as a new and prevalent health behavior is well documented. ${ }^{44}$ Future studies should address the benefits and limitations of each CAM therapy to protect the health of cancer patients.

\section{Acknowledgments}

The Women's Healthy Eating and Living (WHEL) Study was initiated with the support of the Walton Family Foundation and continued with funding from NCI grant CA 69375. Some of the data were collected from General 
Clinical Research Centers, NIH grants M01-RR00070, M01-RR00079, and M01-RR00827. Research related to the development of this paper was funded with support from NRSA National Center for Complementary and Alternative Medicine Fellowship Award 5F31AT004652-02

\section{REFERENCES}

1. Ries, L.; Eisner, M. SEER Survival Monograph: Cancer Survival Among Adults: Cancer SEER Program, 1988-2001, Patient and Tumor Characteristics. National Cancer Institute; Bethesda, MD: 2007. p. 07-6215.

2. Punglia RS, Morrow M, Winer EP, Harris JR. Local therapy and survival in breast cancer. N Engl J Med. 2007; 356:2399-2405. [PubMed: 17554121]

3. Early Breast Cancer Trialists' Collaborative Group. Effects of radiotherapy and surgery in early breast cancer. An overview of the randomized trials. N Engl J Med. 1995; 333:1444-1455. [PubMed: 7477144]

4. Bickell NA, Weidmann J, Fei K, Lin JJ, Leventhal H. Underuse of breast cancer adjuvant treatment: patient knowledge, beliefs, and medical mistrust. J Clin Oncol. 2009; 27:5160-5167. [PubMed: 19770368]

5. Polacek GN, Ramos MC, Ferrer RL. Breast cancer disparities and decision-making among U.S. women. Patient Educ Couns. 2007; 65:158-165. [PubMed: 16870385]

6. Bickell NA, LePar F, Wang JJ, Leventhal H. Lost opportunities: physicians' reasons and disparities in breast cancer treatment. J Clin Oncol. 2007; 25:2516-2521. [PubMed: 17577028]

7. Fagerlin A, Lakhani I, Lantz PM, et al. An informed decision? Breast cancer patients and their knowledge about treatment. Patient Educ Couns. 2006; 64:303-312. [PubMed: 16860523]

8. Katz SJ, Lantz PM, Janz NK, et al. Patient involvement in surgery treatment decisions for breast cancer. J Clin Oncol. 2005; 23:5526-5533. [PubMed: 16110013]

9. Rees L, Weil A. Integrated medicine. BMJ. 2001; 322:119-120. [PubMed: 11159553]

10. Burstein HJ, Gelber S, Guadagnoli E, Weeks JC. Use of alternative medicine by women with early-stage breast cancer. N Engl J Med. 1999; 340:1733-1739. [PubMed: 10352166]

11. Kimby CK, Launso L, Henningsen I, Langgaard H. Choice of unconventional treatment by patients with cancer. J Altern Complement Med. 2003; 9:549-561. [PubMed: 14499031]

12. Velicer CM, Ulrich CM. Vitamin and mineral supplement use among US adults after cancer diagnosis: a systematic review. J Clin Oncol. 2008; 26:665-673. [PubMed: 18235127]

13. NCCAM. CAM Basics. What is Complementary and Alternative Medicine?. U.S. Department of Health and Human Services, National Institutes of Health, National Center for Complementary and Alternative Medicine; Bethesda: 2000.

14. Richardson MA, Sanders T, Palmer JL, Greisinger A, Singletary SE. Complementary/alternative medicine use in a comprehensive cancer center and the implications for oncology. J Clin Oncol. 2000; 18:2505-2514. [PubMed: 10893280]

15. Cassileth BR, Deng G. Complementary and alternative therapies for cancer. Oncologist. 2004; 9:80-89. [PubMed: 14755017]

16. Bardia A, Barton DL, Prokop LJ, Bauer BA, Moynihan TJ. Efficacy of complementary and alternative medicine therapies in relieving cancer pain: a systematic review. J Clin Oncol. 2006; 24:5457-5464. [PubMed: 17135649]

17. Bardia A, Wahner-Roedler DL, Erwin PL, Sood A. Search strategies for retrieving complementary and alternative medicine clinical trials in oncology. Integr Cancer Ther. 2006; 5:202-205. [PubMed: 16880424]

18. Gerber B, Scholz C, Reimer T, Briese V, Janni W. Complementary and alternative therapeutic approaches in patients with early breast cancer: a systematic review. Breast Cancer Res Treat. 2006; 95:199-209. [PubMed: 16254687]

19. Henderson JW, Donatelle RJ. Complementary and alternative medicine use by women after completion of allopathic treatment for breast cancer. Altern Ther Health Med. 2004; 10:52-57. [PubMed: 14727500]

20. Nahleh Z, Tabbara IA. Complementary and alternative medicine in breast cancer patients. Palliat Support Care. 2003; 1:267-273. [PubMed: 16594427] 
21. Shen J, Andersen R, Albert PS, et al. Use of complementary/alternative therapies by women with advanced-stage breast cancer. BMC Complement Altern Med. 2002; 2:8. [PubMed: 12175424]

22. Tagliaferri M, Cohen I, Tripathy D. Complementary and alternative medicine in early-stage breast cancer. Semin Oncol. 2001; 28:121-134. [PubMed: 11254871]

23. Ernst E, Schmidt K, Baum M. Complementary/Alternative therapies for the treatment of breast cancer. A systematic review of randomized clinical trials and a critique of current terminology. Breast J. 2006; 12:526-530. [PubMed: 17238981]

24. Chang EY, Glissmeyer M, Tonnes S, Hudson T, Johnson N. Outcomes of breast cancer in patients who use alternative therapies as primary treatment. Am J Surg. 2006; 192:471-473. [PubMed: 16978951]

25. Pierce JP, Natarajan L, Caan BJ, et al. Influence of a diet very high in vegetables, fruit, and fiber and low in fat on prognosis following treatment for breast cancer: the Women's Healthy Eating and Living (WHEL) randomized trial. Jama. 2007; 298:289-298. PMCID: 2083253. [PubMed: 17635889]

26. Pierce JP, Faerber S, Wright FA, et al. A randomized trial of the effect of a plant-based dietary pattern on additional breast cancer events and survival: the Women's Healthy Eating and Living (WHEL) Study. Control Clin Trials. 2002; 23:728-756. [PubMed: 12505249]

27. Newman V, Rock CL, Faerber S, et al. Dietary supplement use by women at risk for breast cancer recurrence. The Women's Healthy Eating and Living Study Group. J Am Diet Assoc. 1998; 98:285-292. [PubMed: 9508010]

28. Rock CL, Newman V, Flatt SW, et al. Nutrient intakes from foods and dietary supplements in women at risk for breast cancer recurrence. The Women's Healthy Eating and Living Study Group. Nutr Cancer. 1997; 29:133-139. [PubMed: 9427976]

29. Waldron I, Lye D. Family roles and smoking. Am J Prev Med. 1989; 5:136-141. [PubMed: 2787160]

30. Lof M, Hannestad U, Forsum E. Comparison of commonly used procedures, including the doublylabelled water technique, in the estimation of total energy expenditure of women with special reference to the significance of body fatness. Br J Nutr. 2003; 90:961-968. [PubMed: 14667189]

31. Holmes MD, Chen WY, Feskanich D, Kroenke CH, Colditz GA. Physical activity and survival after breast cancer diagnosis. Jama. 2005; 293:2479-2486. [PubMed: 15914748]

32. Yood MU, Owusu C, Buist DS, et al. Mortality impact of less-than-standard therapy in older breast cancer patients. J Am Coll Surg. 2008; 206:66-75. [PubMed: 18155570]

33. Srokowski TP, Fang S, Duan Z, et al. Completion of adjuvant radiation therapy among women with breast cancer. Cancer. 2008; 113:22-29. [PubMed: 18442124]

34. Edwards BK, Brown ML, Wingo PA, et al. Annual report to the nation on the status of cancer, 1975-2002, featuring population-based trends in cancer treatment. J Natl Cancer Inst. 2005; 97:1407-1427. [PubMed: 16204691]

35. Ernst E, Pittler MH, Wider B, Boddy K. Complementary/alternative medicine for supportive cancer care: development of the evidence-base. Supportive Care in Cancer. 2007; 15:565-568. [PubMed: 17093910]

36. Cassileth, BR.; Gubili, J. Integrative Oncology: Complementary Therapies in Cancer Care.. In: Ettinger, DS., editor. Supportive Care in Cancer Therapy. Humana Press; Totowa NJ: 2008. p. 269-277.

37. Post-White J, Kinney ME, Savik K, et al. Therapeutic massage and healing touch improve symptoms in cancer. Integr Cancer Ther. 2003; 2:332-344. [PubMed: 14713325]

38. Walker LG, Walker MB, Ogston K, et al. Psychological, clinical and pathological effects of relaxation training and guided imagery during primary chemotherapy. Br J Cancer. 1999; 80:262268. [PubMed: 10390006]

39. Kolcaba K, Fox C. The effects of guided imagery on comfort of women with early stage breast cancer undergoing radiation therapy. Oncol Nurs Forum. 1999; 26:67-72. [PubMed: 9921569]

40. Carlson LE, Speca M, Patel KD, Goodey E. Mindfulness-based stress reduction in relation to quality of life, mood, symptoms of stress, and immune parameters in breast and prostate cancer outpatients. Psychosom Med. 2003; 65:571-581. [PubMed: 12883107] 
41. Fink BN, Gaudet MM, Britton JA, et al. Fruits, vegetables, and micronutrient intake in relation to breast cancer survival. Breast Cancer Res Treat. 2006; 98:199-208. [PubMed: 16538530]

42. Holmes MD, Stampfer MJ, Colditz GA, et al. Dietary factors and the survival of women with breast carcinoma. Cancer. 1999; 86:826-835. [PubMed: 10463982]

43. Hsieh CY, Santell RC, Haslam SZ, Helferich WG. Estrogenic effects of genistein on the growth of estrogen receptor-positive human breast cancer (MCF-7) cells in vitro and in vivo. Cancer Res. 1998; 58:3833-3838. [PubMed: 9731492]

44. Robotin MC, Penman AG. Integrating complementary therapies into mainstream cancer care: which way forward? Med J Aust. 2006; 185:377-379. [PubMed: 17014406] 


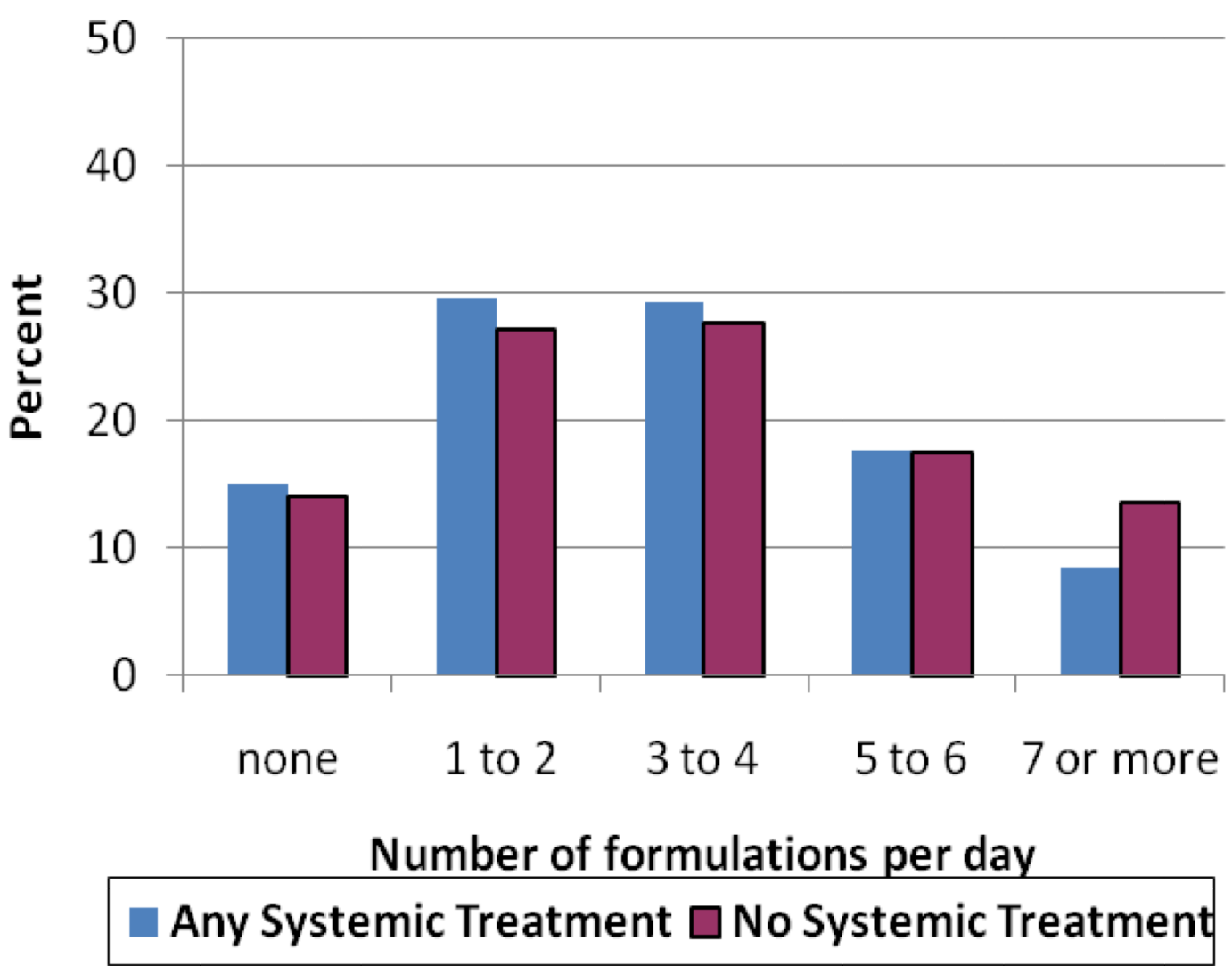

Fig. 1.

Distribution of the number of supplement formulations used by a cohort of breast cancer survivors enrolled in the WHEL Study 


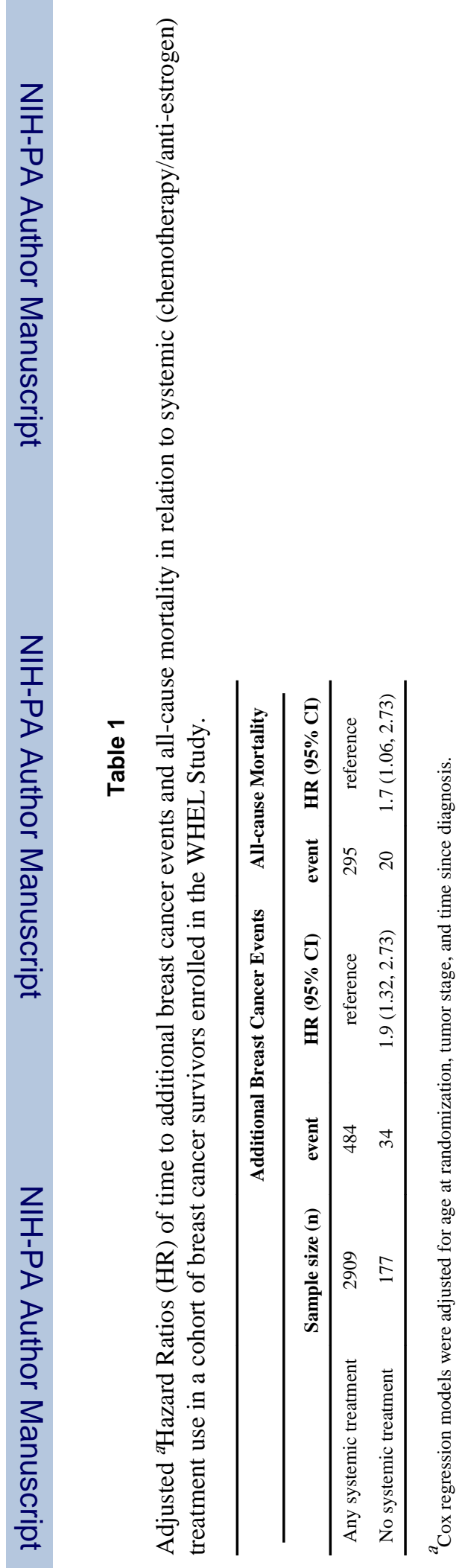




\section{Table 2}

Differences in baseline clinical and demographic characteristics between women who did not receive systemic cancer treatment and those who did receive systemic cancer treatment in a cohort of breast cancer survivors enrolled in the WHEL Study.

\begin{tabular}{|c|c|c|c|}
\hline & No systemic treatment & Any systemic treatment & p-value \\
\hline Sample Size (n) & 177 & 2909 & \\
\hline \multicolumn{4}{|l|}{ Demography } \\
\hline Age $<45$ & 15.8 & 17.7 & 0.21 \\
\hline 45 to 55 & 37.9 & 41.9 & \\
\hline 55 to 65 & 29.9 & 29.0 & \\
\hline$>65$ & 16.4 & 11.4 & \\
\hline Ethnicity (\% non-Hispanic White) & 88.1 & 85.1 & 0.28 \\
\hline Education (\% College \& Beyond) & 45.8 & 54.7 & 0.02 \\
\hline$\%$ Obese (BMI > 30 kg/m2) & 25.4 & 26.0 & 0.98 \\
\hline \multicolumn{4}{|l|}{ Health Behaviors } \\
\hline$\%$ Adequate Physical Activity & 55.2 & 53.6 & 0.70 \\
\hline$\%$ Current Smokers & 4.5 & 4.5 & 0.99 \\
\hline \multicolumn{4}{|l|}{ Health Status } \\
\hline \multicolumn{4}{|l|}{ Year of Cancer } \\
\hline Diagnosis 1991 - 1994 & 27.7 & 21.6 & 0.02 \\
\hline $1995-1997$ & 53.1 & 49.5 & \\
\hline $1998-2000$ & 19.2 & 28.9 & \\
\hline Co-morbid Conditions ( $\%$ with 1 or more) & 52.9 & 44.4 & 0.07 \\
\hline Diabetic Conditions & 6.2 & 4.8 & 0.5 \\
\hline Cardiovascular Diseases & 25.4 & 23.2 & 0.59 \\
\hline Digestive Diseases & 12.4 & 9.9 & 0.38 \\
\hline Arthritis & 23.7 & 20.2 & 0.37 \\
\hline Osteoporosis & 6.2 & 6.4 & \\
\hline
\end{tabular}




\section{Table 3}

Percentage of participants with reported use of each CAM modality for cancer purposes among women who did not receive systemic treatment compared to systemic treatment users in a cohort of breast cancer survivors enrolled in the WHEEL Study ${ }^{a}$.

\begin{tabular}{|c|c|c|c|}
\hline CAM Types & No Systemic Treatment & Any Systemic Treatment & Chi-square p-value \\
\hline Sample size (n) & 141 & 2419 & \\
\hline \multicolumn{4}{|c|}{ Alternative Medicine System } \\
\hline Acupuncture & 6.4 & 7.9 & 0.51 \\
\hline Homeopathic Medicine & 6.4 & 4.7 & 0.35 \\
\hline Naturopathic Medicine & 9.9 & 5.7 & 0.04 \\
\hline \multicolumn{4}{|l|}{$\underline{\text { Mind-Body Medicine }}$} \\
\hline Biofeedback & 0.7 & 2.1 & 0.25 \\
\hline Visual Imagery & 17.7 & 24.2 & 0.08 \\
\hline Meditation/Relaxation & 18.4 & 24.8 & 0.09 \\
\hline Yoga & 7.1 & 10.3 & 0.22 \\
\hline Chanting/Music Therapy & 8.5 & 7.9 & 0.79 \\
\hline Spiritual Healing & 63.9 & 73.7 & 0.19 \\
\hline Qigong/Tai chi & 5.7 & 4.0 & 0.32 \\
\hline \multicolumn{4}{|l|}{ Body-based Medicine } \\
\hline Chiropractic Medicine & 3.5 & 2.6 & 0.48 \\
\hline Massage Therapy & 9.2 & 13.1 & 0.18 \\
\hline \multicolumn{4}{|l|}{$\underline{\text { Energy Medicine }}$} \\
\hline Crystals & 0.7 & 0.9 & 0.81 \\
\hline Magnets & 2.1 & 1.3 & 0.39 \\
\hline Reiki & 4.3 & 4.4 & 0.93 \\
\hline Therapeutic Touch & 2.8 & 4.1 & 0.46 \\
\hline$\%$ using CAM for cancer & 43.3 & 49.7 & 0.14 \\
\hline
\end{tabular}

${ }^{a}$ Estimates were based upon only the participants who completed the CAM survey (total $\left.\mathrm{n}=2562\right)$ (no systemic treatment $=141$ out of 177$)($ any systemic treatment $=2419$ out of 2909). 
Table 4

Percentage of participants with reported use of each dietary supplement formulation among women who did not receive systemic treatment compared to systemic treatment users in a cohort of breast cancer survivors enrolled in the WHEL Study.

\begin{tabular}{lccc}
\hline & No Systemic Treatment & Any Systemic Treatment & Chi-square p-value \\
\hline Sample size (n) & 177 & 2909 & \\
\hline Supplement Category & & & \\
Multivitamin \& mineral & 51.4 & 52.9 & 0.71 \\
Multivitamin & 9.0 & 5.8 & 0.08 \\
Calcium & 44.1 & 46.7 & 0.49 \\
Antioxidant & 10.7 & 9.8 & 0.69 \\
Amino acids/Proteins & 5.1 & 3.4 & 0.23 \\
Vitamin A & 2.3 & 1.7 & 0.59 \\
Vitamin B complex & 28.8 & 19.7 & 0.003 \\
Vitamin C & 46.9 & 41.6 & 0.17 \\
Vitamin D & 1.1 & 1.8 & 0.5 \\
Vitamin E & 46.9 & 46.0 & 0.82 \\
Vitamin K & 0.0 & 0.1 & 0.62 \\
Herbals & 35.6 & 26.0 & 0.005 \\
Herbals -Phytoestrogens & 9.0 & 6.9 & 0.29 \\
Miscellaneous & 22.0 & 16.6 & 0.06 \\
\hline \% High Supplement Use (>3 formulations/day) & 58.8 & 55.3 & 0.37 \\
\hline
\end{tabular}




\section{Table 5}

Adjusted $^{a}$ Hazard Ratios (HR) of time to additional breast cancer events in relation to the use of complementary and alternative medicine (CAM) for cancer purposes and supplement use among women who did not receive systemic treatment in a cohort of breast cancer survivors enrolled in the WHEL Study $(n=177)$.

\begin{tabular}{|c|c|c|c|}
\hline \multirow[b]{2}{*}{ No Systemic Treatment } & \multirow[b]{2}{*}{$\mathbf{N}$} & \multicolumn{2}{|c|}{ Additional breast cancer event } \\
\hline & & Events & HR $(95 \%$ CI $)$ \\
\hline \multicolumn{4}{|l|}{ CAM Use ${ }^{b}$} \\
\hline None & 80 & 12 & reference \\
\hline Any & 61 & 7 & $0.6(.23,1.65)$ \\
\hline \multicolumn{4}{|l|}{ Supplement Use } \\
\hline Low (0 to 2$)$ & 73 & 13 & reference \\
\hline High (3 or more) & 104 & 21 & $1.1(.56,2.26)$ \\
\hline
\end{tabular}

${ }^{a}$ Cox regression models were adjusted for age at randomization, tumor stage, and time since diagnosis.

$b_{\text {Estimates of CAM Use were based upon the participants who completed the CAM survey ( } \mathrm{n}=141)}$ 